\title{
Prospek Pengaturan Cryptocurrency sebagai Mata Uang Virtual di Indonesia (Studi Perbandingan Hukum Jepang Dan Singapura)
}

\author{
F. Yudhi Priyo Amboro ${ }^{1}$ \\ Agustina Christi ${ }^{2}$
}

\begin{abstract}
The development of information technology requires humans in modern times to adjust. Various modern payment instruments have been designed so that they can be used as a means to facilitate transactions. In addition to e-money, in recent years a virtual currency has emerged, known as cryptocurrency. In this paper, researchers formulated the problem form, including: comparison of Japanese and Singapore cyrptocurrency laws, payment systems in Indonesia at this time and then compared the prospects for the development of cryptocurrency whether it can be implemented in Indonesia in facing the globalization of the world.

This research was conducted using a normative research method which was then compared to written regulations, theories, journals obtained from library materials.

The current legal conflict faced by the State is that virtual currencies are not allowed to transact in Indonesia by the government. So this research was conducted with the aim of analyzing comparative law studies related to the prospects for the development of cryptocurrency in Indonesia, as well as examining whether cryptocurrency arrangements could be made in Indonesia.
\end{abstract}

Keywords: Currency, Payment System, Bitcoin

\footnotetext{
${ }^{1}$ Fakultas Hukum Universitas Internasional Batam

${ }^{2}$ Fakultas Hukum Universitas Internasional Batam
} 


\section{A. Latar Belakang}

Bagi suatu Negara, stabilitas keuangan sangatlah penting bagi perkembangan perekonomian Negara, jika diumpamakan bahwa perekonomian Negara merupakan tubuh, maka stabilitas keuangan adalah organ yang ada di dalam tubuh. Sehingga keduanya saling melengkapi keberadaan masing-masing. Dalam perekonomian Negara, uang diperlukan untuk memutar ekonomi kita supaya ekonomi negara terus berkembang. ${ }^{3}$

Secara harafiah pasar merupakan tempat bertemunya para penjual dan pembeli. Tetapi di dalam konteks modern saat ini, pasar telah merupakan suatu mekanisme transaksi yang mana tempat terjadinya transaksi menjadi fleksibel artinya dapat terjadi di manapun.

Saat ini, terus berkembangnya teknologi seiring perkembangan zaman yang pesat telah membawa kemajuan pada seluruh aspek kehidupan manusia. Beriringan dengan berkembangnya era globalisasi ini, juga mempengaruhi perkembangan kegiatan ekonomi dalam masyarakat. Salah satunya yakni merupakan kegiatan e-commerce. Perkembangan $e$ commerce di dunia juga menimbulkan kebutuhan terhadap sistem pembayaran yang aman, cepat dan rahasia.

Perkembangan e-commerce ini ketika dilihat dari sisi lainnya, maka dapat dilihat bahwa telah mendorong perkembangan alat pembayaran yang ada. Dimana semulanya menggunakan pembayaran dengan uang tunai (cash based intruments), kini ada alternatif baru yang berkembang sehingga dapat dilakukan pembayaran tanpa uang tunai yang berbasis kertas (paperless) yang disebut dengan alat pembayaran non tunai (non cash based instruments). Bahkan saat ini berkembang pula uang virtual.

Keberadaan uang virtual ini mulai mendapat perhatian dalam masyarakat, seperti yang diketahui mata uang virtual ini dikenal dengan

\footnotetext{
3 "Pasar Keuangan \&amp; Modal Indonesia - Saham, Obligasi \&amp; Pajak | Indonesia Investments," accessed May 15, 2018, https://www.indonesia-investments.com/id/keuangan/item6.
} 
sebutan mata uang kripto (cryptocurrency) yang mana merupakan hasil perkembangan dari dunia teknologi yang berbasis kriptografi sehingga setiap transaksi yang dilakukan berubah menjadi kode rumit yang tidak mudah digandakan atau berpindah kepada pihak yang tidak mendapatkan izin akses. Hingga saat ini, telah muncul berbagai jenis cryptocurrency yang dapat digunakan dalam transaksi, kurang lebih telah ada sekitar seratusan pilihan. Teknik enkripsi dari mata uang digital atau cryptocurrency ini bertujuan agar dapat mengkontol setiap unit mata uang baru yang beredar serta guna dapat memverifikasi setiap transaksi yang berjalan sendiri secara independen tanpa ada pihak ke-3 yang campur tangan.

Mata uang Rupiah yang saat ini kita gunakan sehari-hari ini diterbikan oleh Bank Indonesia dan diakui oleh Pemerintah sesuai dengan ketentuan Undang-Undang Nomor 7 tahun 2011 tentang Mata Uang. Berbeda dengan cryptocurrency yang terdesentralisasi, mata uang rupiah ini sangat berpengaruh nilainya terhadap perkembangan perekonomian Negara.

Di Indonesia sendiri, mata uang virtual juga telah berkembang. Pesatnya perkembangan penggunaan Bitcoin di kalangan masyarakat inilah yang mendorong Bank Indonesia mengeluarkan pernyataan nomor 20/4/DKom, yang berisi:

"Bank Indonesia menegaskan bahwa virtual currency termasuk bitcoin tidak diakui sebagai alat pembayaran yang sah, sehingga dilarang digunakan sebagai alat pembayaran di Indonesia. Hal tersebut sesuai dengan ketentuan dalam Undang-Undang No. 7 tahun 2011 tentang Mata Uang yang menyatakan bahwa mata uang adalah uang yang dikeluarkan oleh Negara Kesatuan Republik Indonesia dan setiap transaksi yang mempunyai tujuan pembayaran, atau kewajiban lain yang harus dipenuhi dengan uang, atau transaksi keuangan lainnya yang dilakukan di Wilayah Negara Kesatuan Republik Indonesia wajib menggunakan Rupiah.

Pemilikan virtual currency sangat berisiko dan sarat akan spekulasi karena tidak ada otoritas yang bertanggung jawab, tidak terdapat administrator resmi, 
tidak terdapat underlying asset yang mendasari harga virtual currency serta nilai perdagangan sangat fluktuatif sehingga rentan terhadap risiko penggelembungan (bubble) serta rawan digunakan sebagai sarana pencucian uang dan pendanaan terorisme, sehingga dapat mempengaruhi kestabilan sistem keuangan dan merugikan masyarakat. Oleh karena itu, Bank Indonesia memperingatkan kepada seluruh pihak agar tidak menjual, membeli atau memperdagangkan virtual currency.

Bank Indonesia menegaskan bahwa sebagai otoritas sistem pembayaran, Bank Indonesia melarang seluruh penyelenggara jasa sistem pembayaran (prinsipal, penyelenggara switching, penyelenggara kliring, penyelenggara penyelesaian akhir, penerbit, acquirer, payment gateway, penyelenggara dompet elektronik, penyelenggara transfer dana) dan penyelenggara Teknologi Finansial di Indonesia baik Bank dan Lembaga Selain Bank untuk memproses transaksi pembayaran dengan virtual currency, sebagaimana diatur dalam PBI 18/40/PBI/2016 tentang Penyelenggaraan Pemrosesan Transaksi Pembayaran dan dalam PBI 19/12/PBI/2017 tentang Penyelenggaraan Teknologi Finansial.

Bank Indonesia sebagai otoritas di bidang Moneter, Stabilitas Sistem Keuangan dan Sistem Pembayaran senantiasa berkomitmen menjaga stabilitas sistem keuangan, perlindungan konsumen dan mencegah praktik-praktik pencucian uang dan pendanaan terorisme."

Hingga saat ini, cryptocurrency di Indonesia digunakan sebagai alternatif mendapatkan keuntungan bahkan bisnis yang didapatkan keuntungannya dari selisih harga jual dan beli hanya dengan spekulasi. Tujuannya hanya satu yaitu mendapatkan profit dengan cara membeli cryptocurrency saat harga turun dan kemudian dijual kembali saat harganya telah naik hal ini dikarenakan nilai tukar dalam cryptocurrency selalu fluktuatif naik turun dari menit ke menit. Sama halny dengan pergerakan mata uang dunia. Menurut CEO bitcoin Indonesia bapak Oskar Darmawan bahwa sampai saat ini bitcoin masih terus berkembang di Indonesia. $^{4}$

\footnotetext{
4 "Bank Indonesia Akan Buat Aturan Yang Tegaskan Larangan Bitcoin," accessed February 4,
} 2019, https://id.techinasia.com/bank-indonesia-tegaskan-larangan-bitcoin?ref=related\&pos=4. 
Sudah beberapa tahun sejak masuknya cryptocurrency di Indonesia, tetapi ada pernyataan tegas dari bank sentral Indonesia bahwa cryptocurrency bukan merupakan sarana atau alat pembayaran yang sah di Indonesia dan segala resiko (kerugian atau kehilangan) terkait dengan kepemilikan atau penggunaan cryptocurency menjadi resiko masingmasing.

Berdasarkan Pasal 2 Ayat (1) dan (2) Undang-Undang Nomor 7 Tahun 2011 tentang Mata Uang, disebutkan bahwa: "Mata Uang Negara Kesatuan Republik Indonesia adalah Rupiah.” dan "Macam Rupiah terdiri atas Rupiah kertas dan Rupiah logam." Hal ini menyebabkan cryptocurrency sebagai alat pembayaran bertentangan dengan UndangUndang yang berlaku. Tentu dengan lahirnya fenomena seperti ini, timbul masalah hukum seperti tidak adanya kepastian hukum terhadap para pengguna mata uang virtual ini.

Hingga saat ini, Bank Indonesia telah mengeluarkan dua buah Peraturan Bank Indonesia terkait fenomena mata uang virtual ini, yaitu PBI Nomor 18/40/PBI/2016 tentang Penyelenggaraan Pemrosesan Transaksi Pembayaran dan Peraturan Bank Indonesia Nomor: 19/12/PBI/2017 tentang Penyelenggaraan Teknologi Finansial. Pada kedua peraturan yang telah diterbitkan oleh Bank Indonesia tersebut tidak terdapat pengaturan mengenai mata uang virtual sebagai produk digital yang dapat diperjualbelikan melalui media internet.

Peraturan Bank Indonesia secara normatif mengatur mengenai pelarangan mengenai larangan penggunaan mata uang virtual dan sejenisnya ini, padahal di kalangan masyarakat, praktek jual-beli cryptocurrency telah menjadi salah satu fenomena yang tengah booming. Ketidakhadiran regulasi mengenai mata uang virtual ini justru menjadi suatu hal yang meresahkan, baik bagi masyarakat, maupun bagi pengusaha-pengusaha yang bergerak di bidang jual-beli cryptocurrency di Indonesia. Dengan berjalannya kegiatan jual-beli cryptocurrency di 
Indonesia tanpa regulasi, tidak ada lembaga yang dapat bertanggungjawab apabila terjadi hal yang tidak diinginkan di kemudian hari. ${ }^{5}$

Berdasarkan uraian latar belakang di atas, maka penulis tertarik untuk melakukan penelitian yang akan di tuangkan dengan skripsi berjudul: "PROSPEK PENGATURAN CRYPTOCURRENCY SEBAGAI MATA UANG VIRTUAL DI INDONESIA (STUDI PERBANDINGAN HUKUM JEPANG DAN SINGAPURA)" dengan rumusan masalah yaitu: Pertama, Bagaimana studi perbandingan hukum mengenai cryptocurrency di Jepang dan Singapura? Kedua, Bagaimana pengaturan sistem pembayaran dengan mata uang yang ada di Indonesia saat ini? Dan ketiga, Apakah hasil studi perbandingan hukum antara Jepang dan Singapura dapat dijadikan prospek perkembangan cryptocurrency di Indonesia dalam menghadap masa globalisasi dunia?

\section{B. Metode Penelitian}

Penelitian ini dilaksanakan dengan menggunakan metode penelitian hukum normatif. Penelitian yang digunakan untuk mengkaji permasalahan dengan pendekatan studi kepustakaan untuk mengumpulkan hasil data yang kemudian dapat dianalisis ataupun identifikasi permasalahan tersebut yang berakhir mencapai penyelesaian permasalahan dengan metode studi perbandingan hukum. ${ }^{6}$

Jenis atau Sumber data merupakan suatu yang dapat memberikan informasi atas data yang diteliti, pada penelitian penulis ini atas studi perbandingan hukum menggunakan data sekunder. Penjelasan atas data sekunder tersebut yakni dalam penulisan ini data studi yang diperoleh peneliti berupa hasil dari penelitian kepustakaan dan juga data yang telah ada sebelumnya. Data sekunder yang penulis gunakan dalam penelitian ini telah melalui proses yang selektif sehingga seluruh data

\footnotetext{
${ }_{6}^{5}$ Ibid.

6 "Metode Penelitian Hukum Empiris Dan Normatif," accessed April 9, 2019, http://andirustandi.com/baca/386/Metode-Penelitian-Hukum-Empiris-dan-Normatif.html.
} 
yang digunakan memiliki kaitan erat dengan rumusan masalah yang diteliti dan juga harus sesuai dengan apa yang menjadi pertanyaan dalam rumusan masalah tersebut. Dalam data sekunder ini mencakup bahan hukum primer, sekunder dan tersier, yang akan disebutkan oleh penulis seperti yang di bawah ini:

Bahan Hukum Primer yakni bahan hukum yang positif, antara lain: Undang-Undang No 23 Tahun 1999 tentang Bank Indonesia, UndangUndang No 11 Tahun 2008 tentang Informasi dan Transaksi Elektronik (ITE), Undang-Undang No 7 Tahun 2011 tentang Mata Uang, Peraturan Bank Indonesia No 18/40/PBI/2016 Tentang Penyelenggaraan Pemrosesan Transaksi Pembayaran, Peraturan Bank Indonesia No 19/12/PBI/2017 Tentang Penyelenggaraan - Teknologi Finansial, Payment Services Act (Act No. 59 of 2009 - Japan), Securities and Futures Act (Chapter 289 - Singapore), kemudian Bahan Hukum Sekunder yaitu laporan penelitian, jurnal, buku dan sumber dari internet dan Bahan Hukum Tersier adalah bahan yang memberikan informasi atau penjelasan pada bahan hukum primer dan sekunder, seperti Kamus Besar Bahasa Indonesia (KBBI) dan Kamus Hukum.

Dalam menganalisa data ini, penulis menggunakan metode kualitatif yang mana penulis memulai dari menganalisis kualitas dari data tersebut kemudian dilanjutkan dengan diseleksi data-data yang akan digunakan barulah digabungkan dalam suatu pembahasan. Data kualitatif diperoleh dengan mengembangkan teori-teori, konsep-konsep, hingga perundang-undangan dan dibantu dengan perbandingan hasil implementasi pada peraturan perundangan dengan studi perbandingan hukum.

Proses yang dianalisa dimulai dari perbandingan hukum tentang pengaturan cryptocurrency di Jepang dan Singapura, kemudian dibandingkan dengan pengaturan sistem pembayaran di Indonesia dan hasil atas perbandingan tersebut kemudian dibandingkan dengan 
perkembangan cryptocurrency di Indonesia dalam menghadap globalisasi dunia.

\section{Hasil Penelitian dan Pembahasan}

1. Bagaimana studi perbandingan hukum mengenai cryptocurrency di Jepang dan Singapura?

Hadirnya perhatian cryptocurrency di Jepang diawali dengan kasus cybercrime pada perusahaan Mt.Gox pada awal tahun 2014 hingga diajukannya permohonan pailit di Jepang. Mt. Gox merupakan bursa cryptocurrency terbesar pada saat itu yang mana menangani hingga 80 persen perdagangan Bitcoin didunia. Peretasan besar tersebut membuat Mt. Gox akhirnya mengajukan kepailitan kepada otoritas keuangan Jepang setelah mereka kehilangan 850.000 Bitcoin yang kala itu nilainya mencapai 500 juta dolar AS. ${ }^{7}$ Padahal Bitcoin dan cryptocurrency lain diakui sebagai sebuah aktivitas perdagangan dan transaksi yang legal di Jepang. Hampir sepertiga transaksi global bitcoin diperjual-belikan dalam mata uang yen Jepang. ${ }^{8}$

Peristiwa diretasnya Mt. Gox merupakan peristiwa yang menjadikan cryptocurrency sebagai isu yang mengancam Jepang. Salah satu pembuat kebijakan yang menanggapi isu peretasan Mt. Gox pada tahun 2014 adalah Jiro Aichi. Pada tanggal 27 Februari 2014, Jiro Aichi sebagai Vice Finance Minister di Jepang, melakukan konferensi pers terkait dengan kasus Mt. Gox. Dalam konferensi pers tersebut, Jiro Aichi memberikan pernyataan terkait keikutsertaan pemerintah Jepang dalam kasus Mt Gox. Aichi mengatakan bahwa pemerintah Jepang akan ikut menangani kasus Mt Gox jika

\footnotetext{
7 "Regulation of Cryptocurrency," accessed May 18, 2019, https://www.loc.gov/law/help/cryptocurrency/japan.php.

8 "Bursa Bitcoin Besar Di Jepang Diretas, Kerugian Capai Rp 7,12 Triliun - Kumparan.Com," accessed May 26, 2019, https://kumparan.com/@kumparantech/bursa-bitcoin-besar-di-jepangdiretas-kerugian-capai-rp-7-12-triliun.
} 
dibutuhkan. Pada saat kasus Mt. Gox terjadi, belum adanya regulasi yang mengatur cryptocurrency di Jepang, sehingga menjadikan kasus Mt Gox sulit ditangani. Hal ini berkaitan dengan institusi pemerintah mana yang memiliki kewenangan untuk menangani kasus tersebut.

Selain itu, Jiro Aichi juga memberikan pernyataan bahwa jika Bitcoin sebagai cryptocurrency diregulasi, maka diperlukan kerjasama internasional untuk mencegah pelaku tindak kejahatan mengekploitasi loopholes atau poin lemah dalam hukum internasional. Secara tersirat bisa dilihat bahwa pemerintah Jepang mengakui bahwa cryptocurrency bisa menjadi ancaman apabila tidak ada regulasi yang mengaturnya. Mengikuti pernyataan ini, pihak berwenang Jepang menyelidiki lebih lanjut kasus peretasan Mt. Gox bersama dengan pembuat kebijakan dari Amerika Serikat. Sebagai upaya pemerintah Jepang dalam menjaga keamanan nasionalnya, maka pemerintah Jepang melakukan legalisasi terhadap cryptocurrency. ${ }^{9}$

Legalisasi cryptocurrency yang dilakukan melalui Financial Service Agency (FSA) berkaitan dengan pendekatan pertama dalam National Security Strategy untuk memperkuat keamanan siber Jepang dan juga berkaitan dengan kesejahteraan ekonomi Jepang. FSA sendiri adalah lembaga yang mengatur regulasi keuangan di Jepang dan berada dibawah Kementrian Jasa Keuangan Jepang. Melalui FSA untuk melakukan amandemen terhadap Payment Services Act disampaikan ke Parlemen.

Sebelum disampaikan hal tersebut, FSA membentuk study group atau grup pembelajaran terlebih dahulu terkait dengan kecanggihan operasi pembayaran dan penyelesaian pembayaran pada tahun 2014 dan 2015. Pembentukan study group ini karena dipengaruhi adanya peristiwa peretasan Mt. Gox pada tahun 2014. Dapat dilihat bahwa

\footnotetext{
${ }^{9}$ Eulisa Safitri, "KEBIJAKAN MELEGALISASI CRYPTOCURRENCY SEBAGAI UPAYA PEMERINTAH JEPANG MENGAMANKAN KEAMANAN NASIONAL JEPANG," Journal of

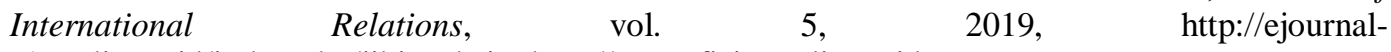
s1.undip.ac.id/index.php/jihiWebsite:http://www.fisip.undip.ac.id.
} 
dibentuknya study group ini juga menggambarkan bahwa intervensi pemerintah Jepang dibutuhkan untuk menangani cryptocurrency, khususnya setelah terjadinya peretasan Mt. Gox.

Dalam laporannya, study group tersebut memberikan beberapa rekomendasi terkait dengan cryptocurrency, yakni: Pengenalan sistem registerasi untuk bisnis pertukaran cryptocurrency, membuat transaksi cryptocurrency sebagai subjek terhadap regulasi money laundering, dan pengenalan sistem untuk melindungi pengguna cryptocurrency. ${ }^{10}$

Dalam bisnis layanan pertukaran mata uang virtual di Jepang, perusahaan diwajibkan untuk mendaftar terlebih dahulu dengan menyerahkan permohonan pendaftaran yang dilengkapi dengan nama pemohon, jenis mata uang virtual yang dikelola hingga sarana layanan penukaran mata uang virtual. Serta wajib mengikuti seluruh prosedur dan kewajiban lainnya sesuai dengan PSA yang telah di amandemen ini.

Adapun peraturan yang berkaitan dengan regulasi anti money laundering yang harus diterapkan oleh platform exchange cryptocurrency atau perusahaan penyedia layanan penukaran mata uang virtual adalah know your customer dalam pembuatan akun, persiapan dan pemeliharaan dari pembukuan dan catatan, melaporkan kegiatan yang mencurigakan, internal control system (peraturan internal, pelatihan, penunjukan manager,dll), dan penggunaan ID orang lain dalam pertukaran cryptocurrency adalah kejahatan. Sehingga harus menggunakan ID pribadi.

Dalam hal ini perusahaan penyedia layanan penukaran mata uang virtual diwajibkan juga untuk memastikan pengelolaan informasi yang aman, melindungi pengguna mata uang virtual, dan memisahkan harta benda pengguna dengan penyedia layanan penukaran mata uang digital. Dengan mulai diterapkannya undang-undang amandemen

${ }^{10}$ Ibid. 
terhadap PSA pada tanggal 01 April 2017 untuk meregulasi cryptocurrency yang mengesahkan penggunaan mata uang virtual yang pada dasarnya memberikan status hukum yang sama dengan mata uang lainnya.

Pemerintah Jepang melalui FSA sebagai badan atau lembaga yang mengawasi transaksi cryptocurrency juga memberikan ultimatum kepada platform exchange cryptocurrency untuk menciptakan satu badan asosiasi yang terpusat pada 24 Oktober 2018. Asosiasi bisnis ini akan menaungi seluruh platform exchange cryptocurrency di Jepang dan diberikan status self-regulatory. Japan Virtual Currency Exchange Association (JVCEA) akan diberikan kewenangan untuk mengatur dan memberikan sanksi kepada pelanggaran dalam pertukaran cryptocurrency. ${ }^{11}$

Di Singapura, Pada 13 Maret 2014, Otoritas Moneter Singapura (MAS) yang diwakilkan oleh Wakil Direktur Pelaksana MAS, Mr Ong Chong Tee mengatakan bahwa mereka akan mengatur perantara mata uang virtual di Singapura untuk mengatasi risiko pencucian uang dan pendanaan teroris (AML / CTF) yang potensial dengan mengambil pendekatan regulasi yang telah ditargetkan untuk mata uang virtual secara khusus dalam hal penanganan resiko pencucian uang dan pendanaan teroris ini, serta menghimbau kepada para konsumen dan pebisnis untuk tetap memperhatikan resiko yang mungkin akan terjadi dalam transaksi. ${ }^{12}$

Kemudian, pada 21 November 2017 Otoritas Moneter Singapura (MAS) meluncurkan konsultasi kedua tentang kerangka pengaturan pembayaran yang diusulkan. Secara khusus, MAS mengeluarkan

\footnotetext{
11 "Japan Grants Cryptocurrency Industry Self-Regulatory Status - Reuters," accessed May 26, 2019, https://www.reuters.com/article/us-japan-cryptocurrency/japan-grants-cryptocurrencyindustry-self-regulatory-status-idUSKCN1MY10W.

12 "MAS to Regulate Virtual Currency Intermediaries for Money Laundering and Terrorist Financing Risks," accessed May 28, 2019, http://www.mas.gov.sg/news-and-publications/mediareleases/2014/mas-to-regulate-virtual-currency-intermediaries-for-money-laundering-and-terroristfinancing-risks.aspx.
} 
Makalah Konsultasi tentang RUU Layanan Pembayaran yang Diusulkan. RUU Layanan Pembayaran (Bill) dimaksudkan untuk merampingkan peraturan layanan pembayaran di bawah satu undangundang, memperluas ruang lingkup kegiatan pembayaran yang diatur untuk mencakup layanan mata uang virtual dan inovasi lainnya, dan mengkalibrasi peraturan sesuai dengan risiko yang ditimbulkan oleh kegiatan ini. ${ }^{13}$

Pada 1 Agustus 2017, MAS merilis pernyataan berikut: "the offer or issue of digital tokens in Singapore will be regulated by MAS if the digital tokens constitute products regulated under the Securities and Futures Act [Chapter 289] (SFA) . . . MAS has observed that the function of digital tokens has evolved beyond just being a virtual currency. For example, digital tokens may represent ownership or a security interest over an issuer's assets or property. Such tokens may therefore be considered an offer of shares or units in a collective investment scheme under the SFA. Digital tokens may also represent a debt owed by an issuer and be considered a debenture under the SFA."

Terjemahan: Tawaran atau masalah token digital di Singapura akan diatur oleh MAS jika token digital merupakan produk yang diatur berdasarkan Securities and Futures Act [Bab 289] (SFA). . MAS telah mengamati bahwa fungsi token digital telah berkembang lebih dari sekedar menjadi mata uang virtual. Misalnya, token digital dapat mewakili kepemilikan atau kepentingan keamanan atas aset atau properti penerbit. Token tersebut karenanya dapat dianggap sebagai penawaran saham atau unit dalam skema investasi kolektif di bawah SFA. Token digital juga dapat mewakili utang yang dimiliki oleh penerbit dan dianggap sebagai surat hutang berdasarkan SFA.

\footnotetext{
13 "MAS Clarifies Regulatory Position on the Offer of Digital Tokens in Singapore," accessed May 28, 2019, http://www.mas.gov.sg/News-and-Publications/Media-Releases/2017/MASclarifies-regulatory-position-on-the-offer-of-digital-tokens-in-Singapore.aspx.
} 
RUU ini akan memberdayakan MAS untuk mengatur layanan pembayaran untuk pencucian uang dan risiko pendanaan terorisme, memperkuat perlindungan untuk dana milik konsumen dan pedagang, menetapkan standar pada manajemen risiko teknologi, dan meningkatkan interoperabilitas solusi pembayaran di berbagai kegiatan pembayaran yang lebih luas. ${ }^{14}$

Jika dilihat dari pembahasan sebelumnya mengenai pengaturan hukum terkait transaksi cryptocurrency di Jepang dan Singapura tersendiri, maka didapatkan hasil persamaan dan perbedaannya sebagai berikut:

Tabel Pengaturan Hukum Transaksi Cryptocurrency di Jepang dan Singapura

\begin{tabular}{|c|c|c|}
\hline Rincian & Penjelasan & Negara \\
\hline Persamaan & $\begin{array}{l}\text { a) Kedua negara ini sama-sama } \\
\text { telah meregulasi Undang- } \\
\text { Undang terkait cryptocurrency. } \\
\text { b) Status cryptocurrency dalam } \\
\text { kegiatan melakukan transaksi } \\
\text { di kedua negara ini adalah } \\
\text { Legal. } \\
\text { c) Memiliki tujuan yang sama } \\
\text { yakni menjaga keamanan } \\
\text { nasional, memperkuat } \\
\text { keamanan jaringan teknologi } \\
\text { informasi, serta melakukan } \\
\text { tindakan pencegahan terlebih } \\
\text { dahulu atas resiko } \\
\text { kemungkinan terjadinya } \\
\text { penyerangan perekonomian } \\
\text { negara. }\end{array}$ & \multirow[t]{2}{*}{$\begin{array}{c}\text { Jepang dan } \\
\text { Singapura }\end{array}$} \\
\hline Perbedaan & $\begin{array}{l}\text { a) Jepang telah ada Undang- } \\
\text { Undang khusus terkait } \\
\text { pengaturan AML/CFT (Anti } \\
\text { money loundring/combating the } \\
\text { financing of terrorism) tentang } \\
\text { anti pencucian uang dan }\end{array}$ & \\
\hline
\end{tabular}

14 "Singapore - The Virtual Currency Regulation Review - Edition 1 - The Law Reviews," accessed May 7, 2019, https://thelawreviews.co.uk/edition/the-virtual-currency-regulation-reviewedition-1/1176666/singapore. 


\begin{tabular}{|l|l|l|}
\hline pencegahan pendanaan teroris & \\
terhadap transaksi & cryptocurrency sedangkan \\
Singapura sedang diatur & Undang-Undang khusus terkait \\
pengaturan AML/CFT untuk & mengatasi resiko yang \\
potensial dengan juga & meningkatkan interoperabilitas \\
solusi pembayaran. & Jepang menetapkan peraturan \\
tentang pajak bagi penghasilan & dari transaksi cryptocurrency \\
sesuai dengan klasifikasi & golongan dengan kisaran mulai \\
dari 5\% - 45\% sedangkan & Singapura alat pembayaran \\
virtual akan dianggap sebagai & penyedia jasa yang akan di \\
kenakan GST (Goods and \\
Services Tax) sebesar 7\%.
\end{tabular}

Sumber: Hasil Olahan Peneliti

2. Bagaimana pengaturan sistem pembayaran dengan mata uang yang ada di Indonesia saat ini?

Yang dimaksud dengan sistem pembayaran yaitu suatu sistem yang memproses kegiatan transaksi pemindahan dana dari satu pihak kepada pihak lainnya dimana terlibat pula beberapa komponen pendukung dalam prosesnya antara lain alat/mesin/aplikasi pembayaran, kliring hingga setelmen. Dalam kegiatan sehari-hari sistem pembayaran ini juga melibatkan beberapa penyelenggara jasa ataupun penyelenggara pendukungnya seperti bank, lembaga keuangan selain bank, dan bahkan perorangan. ${ }^{15}$

Seiring dengan perkembangan zaman, teknologi sistem pembayaran saat ini juga telah berkembang pesat hingga dapat menjadi pilar pendukung stabilitas keuangan Negara, dimana untuk

\footnotetext{
15 "Perkembangan Sistem Pembayaran Di Indonesia - Bank Indonesia," accessed June 28, 2019, https://www.google.com/search?q=Pengaturan+Sistem+Pembayaran+di+Indonesia+Saat+Ini\&oq= Pengaturan+Sistem+Pembayaran+di+Indonesia+Saat+Ini\&aqs=chrome..69i57.1059j0j8\&sourceid $=$ chrome\&ie=UTF-8.
} 
alat pembayaran sendiri yang dulunya hanya menggunakan uang tunai saat ini dapat menjadi non-tunai, kemudian pembayaran dengan nontunai ini semakin berkembang dan semakin canggih hingga tidak berbasis kertas (paperless). Alternatif lainnya jika alat pembayarannya tidak lagi berbasis kertas, maka perlunya didukung oleh infrastruktur teknologi tinggi dan juga suatu legal regime yang berbeda dari alat pembayaran yang berbasis kertas.

Dalam perbankan, sebelum tahun 2000 telah berkembang alat pembayaran dalam bentuk paperless, diawali dengan penerapan bank Indonesia dalam sistem Bank Indonesia Real Time Gross Settlement (BIRTGS) tepat pada tahun 2000 yang kemudian terus berinovasi dalam menciptakan sistem pembayaran elektronik hingga kemudian adanya alat pembayaran tanpa tunai yang kemudian diterapkan dalam Sistem Kliring Nasional (SKN) oleh Bank Indonesia yang merubah penggunaan nota kredit (warkat transfer) menjadi alat pembayaran elektronik yang tidak berbasis kertas (paperless) secara signifikan.

Terjadinya seluruh perkembangan dalam sistem pembayaran saat ini tentunya terdapat konsekuensi terhadap tingkat risiko yang harus dikelola oleh para pelaku sistem pembayaran baik perkembangan tersebut dari alat pembayarannya, proses transaksi hingga pihak penyelenggara tersebut. ${ }^{16}$

Di Indonesia, dalam mengupayakan stabilitas rupiah untuk mendukung majunya perekonomian nasional maka, Bank Indonesia selaku bank sentral Indonesia yang menjadi satu-satunya lembaga keuangan yang memiliki kewenangan untuk mengatur dan menjaga kelancaran jalannya sistem pembayaran dalam negeri. Sehingga dengan adanya kewenangan tersebut, maka Bank Indonesia tentu memiliki hak untuk menetapkan dan memberlakukan kebijakan sistem

${ }^{16}$ Ibid. 
pembayaran di Indonesia melalui Undang-Undang Nomor 23 Tahun 1999 tentang Bank Indonesia. ${ }^{17}$

Dalam hal sistem pembayaran secara tunai hingga non-tunai yang berbasis elektronik di Indonesia telah berkembang mengikuti era globalisasi saat ini, berbeda dengan keberadaan cryptocurrency di Indonesia, sehingga Perkumpulan Pemerhati Bitcoin dan Blockchain Indonesia (PPBBI) bekerjasama dengan International Crypto Currency Promotion Organization (ICCPO) Jepang dalam pertukaran pengetahuan mengenai perkembangan cryptocurrency yang telah berjalan di Jepang dikarenakan Jepang telah melegalkan cryptocurrency dalam transaksi digital. ${ }^{18}$

3. Apakah hasil studi perbandingan hukum antara Jepang dan Singapura dapat dijadikan prospek perkembangan cryptocurrency di Indonesia dalam menghadap masa globalisasi dunia?

Berkembangnya seluruh aspek dalam kehidupan saat ini juga telah mempengaruhi perkembangan era digital bahkan lebih detail menuju dalam sektor keuangan Negara yang terus berkembang hingga terhadap sistem pembayaran. Terdapat data penelitian yang dilakukan oleh Consumer Payment Attitudes Study 2016, sebanyak 80\% masyarakat Indonesia lebih suka menggunakan pembayaran elektronik untuk transaksi. Yang mengartikan bahwa saat ini minat masyarakat terhadap uang tunai makin minim hingga melahirkan komunitas yang dinamakan Cashless Society yaitu masyarakat yang menggunakan lebih menggunakan sistem pembayaran elektronik daripada uang tunai sebagai instrumen kegiatan ekonominya. ${ }^{19}$

\footnotetext{
17 "Sistem Pembayaran: Pengertian, Peran Bank Indonesia, Prinsip Kebijakan," accessed June 30, 2019, https://www.studiobelajar.com/sistem-pembayaran/.

18 "Contoh Jepang, Indonesia Diharapkan Punya Regulasi Jelas Penggunaan Mata Uang Digital Tribunnews.Com," $\quad$ accessed July 2019 , https://www.tribunnews.com/bisnis/2018/09/12/contoh-jepang-indonesia-diharapkan-punyaregulasi-jelas-penggunaan-mata-uang-digital.

19 "Revolusi Sistem Pembayaran Di Era Ekonomi Digital," accessed June 28, 2019, https://blog.mokapos.com/2018/04/25/revolusi-sistem-pembayaran-di-era-ekonomi-digital.
} 
Terdapat penelitian dari Visa yang bertema Consumer Payment Attitudes 2018 dari hasil tersebut telah menggambarkan penduduk masyarakat Indonesia saat ini telah mayoritas siap menghadapi masa depan dengan non-tunai karena persentase menunjukkan angka $82 \%$ yakni 8 dari 10 responden telah mencoba bepergian tanpa tunai. ${ }^{20}$

Penelitian tersebut telah menunjukkan bahwa konsumen di Negara Asia Tenggara telah semakin mengikuti perkembangan digital yang terus bertumbuh dan mengindikasikan masyarakat Indonesia telah sangat sadar akan manfaat tambahan dari pembayaran tanpa tunai.

Presiden Direktur PT Visa Worldwide Indonesia Bapak Riko.A mengatakan bahwa saat ini, semakin banyak masyarakat Indonesia yang memiliki akses terhadap pembayaran nontunai sehingga lebih percaya diri bepergian tanpa tunai. ${ }^{21}$

Kehadiran mata uang virtual di Indonesia secara spesifik belum ada regulasi yang mengaturnya, sehingga kehadiran bitcoin dinyatakan tidak sah sebagai mata uang dan dilarang melakukan transaksi bitcoin dalam wilayah Negara Kesatuan Republik Indonesia yang didukung dengan Undang-Undang Nomor 7 Tahun 2011 tentang Mata Uang dalam pasal 1 disebutkan bahwa :

"Mata Uang adalah uang yang dikeluarkan oleh Negara Kesatuan Republik Indonesia yang selanjutnya disebut Rupiah"

Ditegaskan dengan pasal 11 ayat (3):

"Bank Indonesia merupakan satu-satunya lembaga yang berwenang melakukan Pengeluaran, Pengedaran, dan/ atau Pencabutan dan Penarikan Rupiah”.

20 "Studi Visa: 82\% Masyarakat Indonesia Mulai Tinggalkan Uang Tunai," accessed June 30, 2019, https://www.wartaekonomi.co.id/read221436/studi-visa-82-masyarakat-indonesia-mulaitinggalkan-uang-tunai.html.

${ }^{21}$ Ibid. 
Dengan demikian, suatu alat pembayaran dapat dikatakan legal jika telah memenuhi unsur-unsur dalam alat pembayaran. Akan tetapi, hingga saat ini penggunaan bitcoin telah menyebar secara luas ke seluruh wilayah di Indonesia. Di Indonesia sendiri, telah ada perusahaan atau marketplace khusus bitcoin dengan tujuan agar Indonesia dapat memiliki pergerakan pasar sendiri.

Walau saat ini masyarakat tidak menggunakan bitcoin sebagai alat pembayaran dalam transaksi sehari-hari tapi sejauh ini masyarakat telah melakukan spekulasi dengan mencari keuntungan dari selisih harga yang di perjual-belikan. Segala resiko atau kerugian tentunya ditanggung sendiri oleh penguna.

Pada dasarnya, Indonesia melarang transaksi penggunaan Bitcoin dengan dasar hukum Undang-Undang Nomor 23 Tahun 1999 tentang Bank Indonesia, Undang-Undang Nomor 11 Tahun 2008 tentang Informasi dan Transaksi Elektronik (ITE), Undang-Undang Nomor 7 Tahun 2011 tentang Mata Uang, hingga PBI Nomor 18/40/PBI/2016 tentang Penyelenggaraan Pemrosesan Transaksi Pembayaran dan PBI Nomor 19/12/PBI/2017 tentang Penyelenggaraan Teknologi Finansial.

Pernyataan tegas Bank Indonesia terhadap bitcoin sebagai alat tukar di Indonesia yakni juga memperhatikan konsep dasar bitcoin yang mana sifatnya independen tanpa campur tangan dari lembaga manapun sebagai pihak ke-3. Dengan beberapa pernyataan diatas terkait larangan penggunaan bitcoin, maka dapat dipahami kekhawatiran Negara atas keberadaan mata uang virtual ini. Sehingga, perlu adanya otoritas moneter Negara dalam pengaturan transaksi mata uang virtual agar dapat memberikan pencegahan dan perlindungan bagi Indonesia.

Dari hasil uraian diatas, maka dapat disimpulkan bahwa saat ini cryptocurrency atau mata uang virtual tidak dapat dijadikan alat tukar yang sah dalam transaksi karena belum mempunyai legalitas ataupun 
regulasi yang jelas dari otoritas moneter Negara. Tetapi perlu ditegaskan bahwa Teknologi yang digunakan cryptocurrency sebagaimana sistem desentralisasi yang di tentang pemerintah sebaliknya merupakan keunggulan yakni dengan sistem desentralisasi ini, maka sistem blockchain tidak berkemungkinan terjadi down pada server dikarenakan seluruh jaringan komputer yang aktif merupakan server tersendiri. Sehingga jika terjadinya kerusakan atau pembobolan hacker pada server yang satunya, maka hal tersebut tidak mengganggu transaksi pada server yang lainnya.

Bahwa Negara juga dapat mengatur cryptocurrency dan bekerjasama dengan market place cryptocurrency yang ada di Indonesia, dengan menerapkan kewajiban bertransaksi dengan sistem KYC (Know your customer) sehingga dapat melacak transaksi tanpa adanya pengguna anonim.

\section{Kesimpulan}

Bedasarkan hasil penelitian yang dilakukan oleh Penulis maka dapat disimpulkan bahwa:

1. Cryptocurrency atau mata uang virtual merupakan inovasi baru hasil perkembangan dalam dunia pembayaran digital yang searah dengan perkembangan dunia teknologi dan jaringan internet khususnya dalam sistem pembayaran dan sarana pembayaran digital yang ada saat ini. Produk pertama cryptocurrency dikenal dengan nama Bitcoin yang telah berkembang pesat sejak diciptakan pada tahun 2009, kurs bitcoin pun melonjak naik seiring banyaknya permintaan dan penawaran. Lahirnya bitcoin merupakan hasil akibat dari Great Recession dan krisis keuangan yang terjadi pada tahun 2008 dan merupakan reaksi dari revolusi keuangan yang terjadi selama 20 tahun terakhir. Konsep dasar dari cryptocurrency memiliki standar keamanan tinggi dengan 
sistem kriptografi yang mengubah informasi dari yang dapat dibaca menjadi suatu kode acak yang tidak dapat dibaca dan teknologi pencatatan digital dengan blockchain sendiri yang mendasari berjalannya Bitcoin tanpa bergantung kepada server terpusat dan dengan demikian terhindar dari resiko downtime.

2. Pengaturan hukum terkait cryptocurrency di Jepang dan Singapura. Jepang secara resmi telah melegalkan transaksi penggunaan cryptocurrency serta telah mulai menerapkan undang-undang yang di amandemen pada 01 April 2017 terhadap Payment Service Act (PSA) untuk meregulasi cryptocurrency yang mengesahkan penggunaan mata uang virtual yang pada dasarnya memberikan status hukum yang sama dengan mata uang lainnya. Secara tersirat bisa dilihat bahwa pemerintah Jepang mengakui bahwa cryptocurrency bisa menjadi ancaman apabila tidak ada regulasi yang mengaturnya. Legalisasi cryptocurrency yang dilakukan melalui Financial Service Agency (FSA) berkaitan dengan pendekatan pertama dalam National Security Strategy untuk memperkuat keamanan siber Jepang dan juga berkaitan dengan kesejahteraan ekonomi Jepang. FSA sendiri adalah lembaga yang mengatur regulasi keuangan di Jepang dan berada dibawah Kementrian Jasa Keuangan Jepang. Tujuan dibuat regulasi untuk mencegah terjadinya pengalihan tindakan pidana dengan memverifikasi hal-hal yang ditransaksikan termasuk identifikasi pelanggan dan memeriksa tujuan dari transaksi dilakukan. Dengan diaturnya dan dijelaskannya tentang definisi dari cryptocurrency, regulasi terhadap platform exchange, peraturan terhadap pajak dan regulasi terkait dengan anti-money laundering hingga upaya menjalin kerjasama internasional terkait dengan regulasi cryptocurrency maka dapat dilihat bahwa Jepang telah berusaha meminimalkan terjadinya ancaman serta melindungi masyarakatnya dalam lingkup nasional. Sama halnya dengan Jepang, Singapura juga telah melegalkan transaksi cryptocurrency di negaranya. Melalui Otoritas Moneter Singapura (MAS) dalam Securities and Futures Act yang merupakan 
undang-undang utama yang mengatur sekuritas dan investasi di Singapura. Lembaga keuangan yang beroperasi di Singapura diharuskan menerapkan kontrol yang kuat untuk mendeteksi dan menghalangi aliran dana gelap melalui sistem keuangan Singapura. Kontrol tersebut mencakup perlunya lembaga keuangan untuk mengidentifikasi dan mengetahui pelanggan mereka, melakukan peninjauan akun secara teratur, dan memantau dan melaporkan setiap transaksi yang mencurigakan. Persyaratan pada lembaga keuangan diatur dalam MAS Notices tentang Pencegahan Pencucian Uang dan Penanggulangan Pendanaan Terorisme (Pemberitahuan AML / CFT).

3. Saat ini cryptocurrency atau mata uang virtual tidak dapat dijadikan alat tukar dalam transaksi karena belum mempunyai legalitas ataupun regulasi yang jelas dari otoritas moneter Negara. Pada dasarnya, Indonesia melarang transaksi penggunaan Bitcoin dengan dasar hukum Undang-Undang Nomor 23 Tahun 1999 tentang Bank Indonesia, Undang-Undang Nomor 11 Tahun 2008 tentang Informasi dan Transaksi Elektronik (ITE), Undang-Undang Nomor 7 Tahun 2011 tentang Mata Uang, hingga PBI Nomor 18/40/PBI/2016 tentang Penyelenggaraan Pemrosesan Transaksi Pembayaran dan PBI Nomor 19/12/PBI/2017 tentang Penyelenggaraan Teknologi Finansial atas pertimbangan pemerintah yakni pergerakan harga bitcoin yang fluktuatif berpotensi mengganggu stabilitas keuangan Negara dikarenakan kemungkinan terjadinya penggelembungan nilai uang virtual akibat tren bitcoin, kemudian juga khawatir keberadaan mata uang virtual ini disalah gunakan oleh pihak tertentu dalam transaksi jual-beli barang terlarang serta pencucian uang bahkan peretasan sistem. Akan tetapi, perlu adanya otoritas moneter Negara dalam pengaturan transaksi mata uang virtual agar dapat memberikan pencegahan dan perlindungan bagi Indonesia. Apabila telah diakuinya bitcoin sebagai alat pembayaran yang sah maka, Negara dapat melakukan pengenaan pajak atas transaksi ataupun bagi pihak penyedia jasa yang mana dapat meningkatkan pendapatan Negara 
dalam membangun infrastruktur Negara hingga dengan adanya dibuat regulasi maka juga melakukan pencegahan terlebih dahulu atas kemungkinan terjadinya transaksi tindak pidana. Jika sebaliknya pemerintah tetap tidak melakukan tindakan atau pernyataan jelas terkait keberadaan mata uang virtual ini, maka akibatnya alur lalu lintas transaksi tidak diawasi yang mana kerugian atas pendapatan Negara yang terus hangus menjadi kerugian sumber pendapatan tambahan Negara, bahkan Negara juga tidak ada pencegahan jika terjadinya kasus tertentu. Hingga tidak dapat memonitoring akan adanya transaksi mencurigakan yang terindikasi adanya tindakan pidana baik dalam maupun luar negeri. 


\section{Daftar Pustaka}

\section{Buku}

Dimaz Ankaa Wijaya \& Oscar Darmawan. Blockchain Dari Bitcoin Untuk Dunia. Jasakom, 2017.

Nubika, Ibrahim. BITCOIN ; Mengenal Cara Baru Berinvestasi Generasi Milenial. Edited by Arvin Mahardika. I. Yogyakarta: Genesis Learning, 2018.

"Pengantar Ilmu Hukum - Muhamad Sadi Is, S.HI., M.H. - Google Buku." Accessed May 7, 2019.

https://books.google.co.id/books?i=H9xDDwAAQBAJ\&pg=PA21 $3 \& \mathrm{lpg}=\mathrm{PA} 213 \& \mathrm{dq}=$ studi+perbandingan+hukum+alan+watson\&so urce $=$ bl\&ots $=$ oKuwf32bLu\&sig $=$ ACfU3U11m7CmCmH1tRW2F wAEwX2Wra11Jw\&hl=id\&sa=X\&ved=2ahUKEwiA2PKM0ITiA hVimuYKHfAQADoQ6AEwCXoECAkQAQ\#v=onepage \&q=stud i .

\section{Peraturan Perundang-Undangan:}

Indonesia, Undang - Undang Bank Indonesia. UU Nomor 23 Tahun 1999. Indonesia, Undang - Undang Informasi dan Transaksi Elektronik. UU Nomor 11 Tahun 2008.

Indonesia, Undang - Undang Mata Uang. UU Nomor 7 Tahun 2011. Indonesia, Peraturan Bank Indonesia Tentang Penyelenggaraan Pemrosesan Transaksi Pembayaran. PBI Nomor 18/40/PBI/2016.

Indonesia, Peraturan Bank Indonesia Tentang Penyelenggaraan Teknologi Finansial. PBI Nomor 19/12/PBI/2017.

Japan, Payment Service Act No. 59 of 2009.

Singapore, Securities and Futures Act Chapter 289.

\section{Bahan Internet}

"Ini Perbandingan Tarif UWTO Lama Dan Baru Di Batam." Accessed December 30, 2018. https://www.batamnews.co.id/berita-16923ini-perbandingan-tarif-uwto-lama-dan-baru-di-batam.html.

“9 Peristiwa Penting Dalam Sejarah Bitcoin - Apa Itu Bitcoin.” Accessed May 20, 2019. http://apaitubitcoin.com/9-peristiwa-penting-dalamsejarah-bitcoin/.

"Akhir Tahun Ini, Singapura Adopsi Sistem Pembayaran Dengan QR Code | Katadata News.” Accessed July 19, 2019. https://katadata.co.id/berita/2018/07/13/akhir-tahun-ini-singapuraadopsi-sistem-pembayaran-dengan-qr-code.

"Arti Kata Uang - Kamus Besar Bahasa Indonesia (KBBI) Online." Accessed February 16, 2019. https://kbbi.web.id/uang.

"Bank Indonesia Akan Buat Aturan Yang Tegaskan Larangan Bitcoin." Accessed February 4, 2019. https://id.techinasia.com/bankindonesia-tegaskan-larangan-bitcoin?ref=related\&pos $=4$.

"Buletin Interaksi PPI Jepang Edisi Ke-18 - Desember 2012 by PPI Jepang - Issuu." Accessed May 25, 2019. https://issuu.com/ppijepang/docs/interaksi18-des12. 
"Bursa Bitcoin Besar Di Jepang Diretas, Kerugian Capai Rp 7,12 Triliun Kumparan.Com.” Accessed May 26, 2019.

https://kumparan.com/@kumparantech/bursa-bitcoin-besar-dijepang-diretas-kerugian-capai-rp-7-12-triliun.

"Cash-Obsessed Japan Slowly Buying into Digital Payment Systems | The Japan Times." Accessed July 18, 2019.

https://www.japantimes.co.jp/news/2019/03/29/business/cashobsessed-japan-slowly-buying-digital-paymentsystems/\#.XTCRgugzbIU.

"Cegah Pemalsuan, Jepang Terapkan Teknologi Canggih Pada Uang Kertas Baru.” Accessed July 18, 2019.

https://internasional.kompas.com/read/2019/04/10/12352661/cegah -pemalsuan-jepang-terapkan-teknologi-canggih-pada-uang-kertasbaru.

“Contoh Jepang, Indonesia Diharapkan Punya Regulasi Jelas Penggunaan Mata Uang Digital - Tribunnews.Com.” Accessed July 18, 2019. https://www.tribunnews.com/bisnis/2018/09/12/contoh-jepangindonesia-diharapkan-punya-regulasi-jelas-penggunaan-mata-uangdigital.

"Crypto Tokens The Good The Bad and The Ugly." Accessed May 28, 2019. http://www.mas.gov.sg/News-and-Publications/Speechesand-Monetary-Policy-Statements/Speeches/2018/Crypto-TokensThe-Good-The-Bad-and-The-Ugly.aspx.

DANELLA, and TIARA DHANA. "BITCOIN SEBAGAI ALAT PEMBAYARAN YANG LEGAL DALAM TRANSAKSI

ONLINE." Kumpulan Jurnal Mahasiswa Fakultas Hukum 0, no. 0 (2015).

http://hukum.studentjournal.ub.ac.id/index.php/hukum/article/view/ 898/889.

"Ini Cara Singapura Dorong Sistem Pembayaran Digital - Kabar24

Bisnis.Com.” Accessed July 19, 2019.

https://kabar24.bisnis.com/read/20180621/19/808069/ini-carasingapura-dorong-sistem-pembayaran-digital.

Ini Lima Visi Sistem Pembayaran Indonesia Hadapi Perkembangan Digitalisasi.” Accessed June 30, 2019.

https://keuangan.kontan.co.id/news/ini-lima-visi-sistempembayaran-indonesia-hadapi-perkembangan-digitalisasi.

“Japan's Virtual Currency Regulation and Its Recent Developments Masakazu \&quot;Masa\&quot; Masujima,” 2018. http://startupinnovators.jp/.

"Japan: Bitcoin to Be Regulated | Global Legal Monitor." Accessed May 18, 2019. https://www.loc.gov/law/foreign-news/article/japanbitcoin-to-be-regulated/.

"Japan Grants Cryptocurrency Industry Self-Regulatory Status - Reuters." Accessed May 26, 2019. https://www.reuters.com/article/us-japancryptocurrency/japan-grants-cryptocurrency-industry-selfregulatory-status-idUSKCN1MY10W. 
"Japanese Law Translation - [Law Text] - Payment Services Act." Accessed May 18, 2019.

http://www.japaneselawtranslation.go.jp/law/detail/?vm=02\&re $=02$ $\& \mathrm{id}=3078 \& 1 \mathrm{lvm}=02$.

"Japanese Regulator to Host Regular Global Cryptocurrency Roundtable Bitcoin News.” Accessed May 26, 2019. https://news.bitcoin.com/japanese-regulator-cryptocurrencyroundtable/.

"Line Segera Buka Layanan Penukaran Mata Uang Digital." Accessed July 18, 2019.

https://www.suara.com/tekno/2019/06/23/092455/line-segera-bukalayanan-penukaran-mata-uang-digital.

"MAS Clarifies Regulatory Position on the Offer of Digital Tokens in Singapore." Accessed May 28, 2019.

http://www.mas.gov.sg/News-and-Publications/Media-

Releases/2017/MAS-clarifies-regulatory-position-on-the-offer-ofdigital-tokens-in-Singapore.aspx.

"MAS to Regulate Virtual Currency Intermediaries for Money Laundering and Terrorist Financing Risks." Accessed May 28, 2019.

http://www.mas.gov.sg/news-and-publications/mediareleases/2014/mas-to-regulate-virtual-currency-intermediaries-formoney-laundering-and-terrorist-financing-risks.aspx.

"Mekanisme Dan Kondisi Cryptocurrency Di Indonesia - Arief Subagja Medium." Accessed February 16, 2019.

https://medium.com/@ riefbagja/mekanisme-dan-kondisicryptocurrency-di-indonesia-a7443d45e4ec.

"Mengenal Cryptocurrency Dan Mekanisme Transaksinya | Dailysocial." Accessed February 15, 2019. https://dailysocial.id/post/mengenalcryptocurrency-dan-mekanisme-transaksinya.

"Metode Penelitian Hukum Empiris Dan Normatif." Accessed April 9, 2019. http://andirustandi.com/baca/386/Metode-Penelitian-HukumEmpiris-dan-Normatif.html.

"Modul Perbandingan Hukum." Accessed July 27, 2019. https://www.scribd.com/document/366593112/ModulPerbandingan-Hukum.

"Pasar Keuangan \&amp; Modal Indonesia - Saham, Obligasi \&amp; Pajak | Indonesia Investments." Accessed May 15, 2018. https://www.indonesiainvestments.com/id/keuangan/item6."Payment Gateway Integration Options in Singapore - Chargebee's SaaS Dispatch." Accessed July 19, 2019. https://www.chargebee.com/blog/payment-gatewayssingapore/.

"Pengertian Sistem Pembayaran, Prinsip-Prinsip Dasar Sistem Pembayaran, Jenis-Jenis Sistem Pembayaran, Lembaga-Lembaga Dalam Sistem Pembayaran, Jenis-Jenis Alat Pembayaran Beserta Penjelasannya Terlengkap | Edukasi Indonesia (Edukasinesia.Com)," accessed February 17, 2019, https://www.edukasinesia.com/2017/03/pengertian-sistempembayaran-prinsip-prinsip-dasar-sistem-pembayaran-jenis-jenis-sistempembayaran-lembaga-lembaga-dalam-sistem-pembayaran-jenis-jenis- 
alat-pembayaran-beserta-penjelasannya-terlengkap.html\#.

"Pengertian Uang - Definisi, Fungsi, Syarat Dan Jenis Uang | Romadacade," accessed February 5, 2019, https://www.romadecade.org/pengertianuang/\#!

"Pengertian Uang, Sejarah, Fungsi, Syarat, Jenis, Dan Teorinya." Accessed February 5, 2019. https://uangindonesia.com/tentanguang-pengertian-sejarah-fungsi-syarat-jenis-dan-teorinya/.

Pengertian Uang Menurut Para Ahli Terlengkap." Accessed February 16, 2019. https://www.gurupendidikan.co.id/18-pengertian-uangmenurut-para-ahli-terlengkap/.

Perkembangan Sistem Pembayaran Di Indonesia - Bank Indonesia." Accessed June 28, 2019. https://www.google.com/search?q=Pengaturan+Sistem+Pembayara $\mathrm{n}+\mathrm{di}+$ Indonesia+Saat+Ini\&oq=Pengaturan+Sistem+Pembayaran $+\mathrm{d}$ $\mathrm{i}+$ Indonesia+Saat+Ini\&aqs $=$ chrome..69i57.1059j0j8\&sourceid $=\mathrm{chr}$ ome\&ie $=$ UTF-8.

Regulasi Dan Kebijakan Terkait Mata Uang Kripto Sebagai Alat Pembayaran Di Indonesia Oleh Maura Maghfira Halaman All Kompasiana.Com." Accessed March 27, 2019. https://www.kompasiana.com/ramautura/5a02a9f58325cc3e613fd7 c2/regulasi-dan-kebijakan-terkait-mata-uang-kripto-sebagai-alatpembayaran-di-indonesia?page $=$ all .

Regulation of Cryptocurrency." Accessed May 18, 2019. https://www.loc.gov/law/help/cryptocurrency/japan.php.

Revolusi Sistem Pembayaran Di Era Ekonomi Digital.” Accessed June 28, 2019. https://blog.mokapos.com/2018/04/25/revolusi-sistempembayaran-di-era-ekonomi-digital.

Safitri, Eulisa. "KEBIJAKAN MELEGALISASI CRYPTOCURRENCY SEBAGAI UPAYA PEMERINTAH JEPANG MENGAMANKAN KEAMANAN NASIONAL JEPANG." Journal of International Relations. Vol. 5, 2019. http://ejournals1.undip.ac.id/index.php/jihiWebsite:http://www.fisip.undip.ac.id.

Sebatas, Tak, and Kegiatan Keuangan. "Teknologi Blockchain, Teknologi Masa Depan." Accessed March 22, 2019. https://fintech.id/Idea PDF/FinTech Talk - Opinion Editorial 45 - Teknologi Blockchain Oscar Darmawan - 10 Okt 2017_1.pdf.

"Sejarah Cryptocurrency Sebelum Era Bitcoin - Kriptokoin." Accessed May 20, 2019. https://kriptokoin.wordpress.com/2016/07/01/sejarahcryptocurrency-sebelum-era-bitcoin/.

"Singapore - The Virtual Currency Regulation Review - Edition 1 - The Law Reviews." Accessed May 7, 2019. https://thelawreviews.co.uk/edition/the-virtual-currency-regulationreview-edition-1/1176666/singapore.

"Sistem Hukum Negara-Negara Asia Tenggara - Jurnal Hukum Dan Pembangunan Ke-37 No.2 April-Juni 2007.” Accessed May 27, 2019.

http://jhp.ui.ac.id/index.php/home/article/download/1479/1394.

"Sistem Pembayaran - Bank Sentral Republik Indonesia." Accessed 
February 17, 2019. https://www.bi.go.id/id/sistempembayaran/Contents/Default.aspx.

"Sistem Pembayaran: Pengertian, Peran Bank Indonesia, Prinsip Kebijakan." Accessed June 30, 2019. https://www.studiobelajar.com/sistem-pembayaran/.

Somadiyono, Sigit. "RELEVANSI UU No. 7 TAHUN 2011 TENTANG MATA UANG DENGAN FENOMENA MUNCULNYA MATA UANG VIRTUAL, STUDI KASUS FENOMENA BITCOIN DI INDONESIA." Jurnal Ilmiah Universitas Batanghari Jambi 14, no. 2 (March 13, 2017): 64-69. http://ji.unbari.ac.id/index.php/ilmiah/article/view/284/276.

"Studi Visa: 82\% Masyarakat Indonesia Mulai Tinggalkan Uang Tunai." June 30 , 2019. https://www.wartaekonomi.co.id/read221436/studi-visa-82masyarakat-indonesia-mulai-tinggalkan-uang-tunai.html.

"Virtual Currencies: Issues Remain after Payment Services Act Amended." Accessed May 25, 2019. http://fis.nri.co.jp/ /media/Files/publication/kinyuitf/en/2016/lakyaravol243.pdf. 